\title{
Impact wear resistance of plasma diffusion treated and duplex treated/PVD-coated Ti-6Al-4V alloy
}

\author{
G. Cassar ${ }^{\text {a,* }}$, S. Banfield ${ }^{\text {a,b }}$, J.C. Avelar-Batista Wilson ${ }^{\text {b }}$, J. Housden ${ }^{\text {b }}$, A. Matthews ${ }^{\text {a }}$, A. Leyland ${ }^{\text {a }}$ \\ a Department of Materials Science and Engineering, University of Sheffield, Sir Robert Hadfield Building, Mappin St., Sheffield S1 3JD, UK \\ b Tecvac Ltd, Buckingway Business Park, Swavesey, Cambridge CB24 4UG, UK
}

\section{A R T I C L E I N F O}

\section{Article history:}

Received 5 August 2011

Accepted in revised form 29 October 2011

Available online 6 November 2011

\section{Keywords:}

Triode plasma diffusion

PVD

Ti-6Al-4V

Impact wear

\begin{abstract}
A B S T R A C T
In this paper dynamic ball-on-plate impact wear testing is utilised to evaluate the intrinsic fatigue strength of the surface of triode plasma diffusion treated, single-layered TiN-, CrAlN-, and WC/C-coated and duplex diffusion treated/PVD-coated Ti-6Al-4V. The test is used to assess the resistance of surfaces to dynamic, highcycle loading caused by the repeated impact of a cemented carbide ball. The subsequent observation and comparison of the wear craters produced (and their measured volumes) was used to identify which diffusion treatment (or treatment/coating combination) provided the most marked reduction in contact-induced deformation and overall improvement in wear behaviour. A combination of nanoindentation, Knoop hardness microindentation, scratch adhesion, stylus profilometry, optical microscopy, scanning electron microscopy, energy-dispersive X-ray spectroscopy and atomic force microscopy test and evaluation methods, was used to characterise the surfaces under investigation. Experimental results revealed that triode plasma diffusion treatments can provide exceptional improvements in the impact fatigue resistance, particularly when the diffusion process has been designed to maximise the resultant hardened case depth. Also, amongst the three coatings tested, PVD CrAIN was found to be the most suitable for applications involving such dynamic impact loading. Finally, the results presented show that an appropriate sequential triode plasma oxidation and nitriding diffusion pretreatment, in combination with a hard and tough PVD ceramic coating, can provide a significant reduction in surface impact wear when compared to either plasma diffusion treatments alone, or PVD ceramic coatings deposited on non-pretreated Ti-alloy substrates.
\end{abstract}

(c) 2011 Elsevier B.V. All rights reserved.

\section{Introduction}

Ball-on-plate impact testing, as originally conceived by Knotek et al. [1], involves repetitively accelerating a hard ball, typically cemented tungsten carbide, towards a stationary flat sample. This test can be used to assess the local fatigue strength of surface-modified materials. Impact wear may be an important surface degradation mechanism in many applications such as for tools used in interrupted-cutting operations (e.g. milling), as well as during forming and punching, but also in many moving machine elements. In all these applications coatings are commonly used and the system endurance may not depend on its resistance to conventional sliding wear but rather on the occurrence of debonding of the coating from the substrate (adhesive failure), fracture of the coating (cohesive failure), or subsurface (fatigue) fracture. Ball-on-plate impact testing has been proven to be a suitable technique to characterise the fatigue behaviour of coating-substrate systems and particularly cohesion (within the coating) and adhesion (between the

\footnotetext{
* Corresponding author. Tel.: + 3562340 2140; fax: + 35621343577 E-mail address: glenn.cassar@um.edu.mt (G. Cassar).
}

pair) [1-4]. In addition, a direct correlation between interruptedcutting performance and coating impact resistance has also been shown [5].

The study of resistance to impact loading (and the avoidance of resulting severe wear mechanisms) is particularly relevant for light alloys with relatively low elastic moduli which are therefore much more compliant (compared to most machine-tool type steels). The low yield strength of many such materials allows gross plastic deformation to occur under the ball contact surface, leading potentially to cracking and exfoliation of the coating. In this study, the surface fatigue behaviour of Ti-6Al-4V is investigated and the effect of several surface engineering treatments is observed. Although previous work [6-8] has already demonstrated a very significant improvement in the resistance to sliding wear of triode plasma diffusion treated and PVD-coated Ti-6Al-4V, it is also important to investigate whether such surface hardening techniques can also lead to an increased resistance to cyclic impact loading. While thermochemical diffusion pretreatments may be beneficial to the coating impact response (by improving substrate mechanical load support), these may also have deleterious consequences such as (i) creating hard brittle layers which could fail under impact or cyclic fatigue loading, compromising 
PVD coating integrity, or (ii) inducing significant softening of the substrate as a consequence of the thermal cycle involved in (particularly) the plasma diffusion treatment [9].

\section{Experimental details}

The nominal chemical composition of the Ti-6Al-4V alloy used in this work was $6.01 \mathrm{wt} . \% \mathrm{Al}, 4.08 \mathrm{wt} . \% \mathrm{~V}$, balance Ti. The test coupons had a core hardness of $375 \pm 10 \mathrm{HK}_{0.025}$ and were polished to a mean surface roughness $\left(R_{a}\right)$ of $0.03 \pm 0.01 \mu \mathrm{m}$.

The base material was diffusion-pretreated by triode plasma nitriding or combined oxidation/nitriding in a modified Tecvac IP70L commercial PVD coating system, using a low-pressure d.c. triode configuration $[10,11]$ and additional radiative heating. Triode enhanced-plasma diffusion treatments were carried out for a total of $4 \mathrm{~h}$ in a mixture of $70 \%$ partial pressure of nitrogen or oxygen and $30 \%$ partial pressure of argon, at a total gas pressure of $0.4 \mathrm{~Pa}$. The process description and the abbreviated designations are illustrated in Table 1.

The specimens, untreated or diffusion-treated, were coated either with TiN, deposited using an electron-beam (EB) plasma-assisted (PA) PVD system (Tecvac IP70) or with CrAlN, deposited using a twin-EB PAPVD machine (Tecvac IP35). Thermionic plasma enhancement was provided by an additional electron-emitting cathode in the form of a hot tungsten filament, biased at $-200 \mathrm{~V}$. Samples were firstly diode sputter cleaned in Ar, then a thin interlayer with a thickness between 0.1 and $0.2 \mu \mathrm{m}$ was deposited ( $\mathrm{Ti}$ in the case of $\mathrm{TiN}$, and $\mathrm{Cr}+\mathrm{CrN}$ for CrAlN) under a pressure of $0.3 \mathrm{~Pa}$ and triode plasma conditions. Finally, $2.8 \pm 0.2 \mu \mathrm{m}$ thick TiN or $2.0 \pm 0.2 \mu \mathrm{m}$ thick CrAlN ceramic coatings were deposited. During the coating stage the maximum substrate temperature ranged between 400 and $450{ }^{\circ} \mathrm{C}$.

WC/C coatings were produced using a Tecvac d.c. unbalanced magnetron sputtering PVD machine. A $\sim 0.3 \mu \mathrm{m} \mathrm{Cr}$ interlayer was first deposited and then a tungsten carbide phase was grown using magnetron sputtering, while the diamond-like carbon phase was introduced simultaneously by plasma-assisted CVD from an acetylene $\left(\mathrm{C}_{2} \mathrm{H}_{2}\right)$ and Ar plasma. During coating deposition the substrate temperature ranged between 200 and $250{ }^{\circ} \mathrm{C}$. The total thickness of WC/C coatings was $2.5 \pm 0.1 \mu \mathrm{m}$.

\subsection{Characterisation}

Knoop hardness microindentation measurements were performed on polished substrate cross-sections using a Mitutoyo HM-01 microhardness tester, set at a load of $25 \mathrm{gf}(1 \mathrm{gf}=9.81 \mathrm{mN})$ and a $20 \mathrm{~s}$

Table 1

Ti-6Al-4V samples selected for impact testing.

\begin{tabular}{|c|c|c|c|c|c|}
\hline \multirow[t]{2}{*}{ Group } & \multirow[t]{2}{*}{ Designation } & \multicolumn{4}{|c|}{ Diffusion treatment processing parameters } \\
\hline & & $\begin{array}{l}\text { Cathode } \\
\text { bias (V) }\end{array}$ & $\begin{array}{l}\text { Duration } \\
\text { (h) }\end{array}$ & $\begin{array}{l}\text { Working } \\
\text { gas }\end{array}$ & $\begin{array}{l}\text { Temperature } \\
\left({ }^{\circ} \mathrm{C}\right)\end{array}$ \\
\hline \multirow[t]{3}{*}{ Reference } & Untreated & - & - & - & - \\
\hline & LV-TPN(HT) & -200 & 4 & $\mathrm{~N}_{2}$ & 800 \\
\hline & HV-TPN & -1000 & 4 & $\mathrm{~N}_{2}$ & 700 \\
\hline \multirow[t]{2}{*}{$\begin{array}{l}\text { Diffusion treated } \\
\text { (and duplex) }\end{array}$} & $\begin{array}{l}\text { LHV-TPN } \\
(+ \text { TiN/CrAlN })\end{array}$ & $\begin{array}{l}-200 \\
-1000\end{array}$ & $\begin{array}{l}3 \\
1\end{array}$ & $\begin{array}{l}\mathrm{N}_{2} \\
\mathrm{~N}_{2}\end{array}$ & $\begin{array}{l}700 \\
700\end{array}$ \\
\hline & LHV-TPON & $\begin{array}{l}-200 \\
-200 \\
-1000\end{array}$ & $\begin{array}{l}1 \\
2 \\
1\end{array}$ & $\begin{array}{l}\mathrm{O}_{2} \\
\mathrm{~N}_{2} \\
\mathrm{~N}_{2}\end{array}$ & $\begin{array}{l}700 \\
700 \\
700\end{array}$ \\
\hline Coated only & $\begin{array}{l}\text { TiN/CrAlN/ } \\
\text { WCC }\end{array}$ & - & - & - & - \\
\hline
\end{tabular}

LV and HV denote Low Voltage and High Voltage, respectively. LHV represents a Low Voltage stage followed by a High Voltage stage and HT signifies a High Temperature process. dwell time. The test method used followed the relevant standard for Knoop hardness testing of metallic materials - BS EN ISO 4545-1:2005 [12]. Surface nanoindentation measurements were performed using a Hysitron Inc. Triboscope ${ }^{\mathrm{TM}}$ equipped with a Berkovich triangularpyramidal diamond indenter. Fifteen indentations were made for each sample at maximum loads of around $10 \mathrm{mN}$ and $5 \mathrm{mN}$ for coated and diffusion-treated samples, respectively. For consistency, Knoop microindentation hardness values measured in cross-section have also been converted to GPa.

Optical microscopy was carried out using a Polyvar Met research microscope fitted with Axio Cam (Zeiss) digital camera, while for electron microscopy a JEOL JSM 6400 scanning electron microscope (SEM) was operated at 15 to $20 \mathrm{kV}$.

A commercial Revetest ${ }^{\mathrm{TM}}$ scratch tester (CSM Instruments, Switzerland) was also used to assess coating adhesion. A loading rate of $10 \mathrm{~N} / \mathrm{mm}$ was applied and the sample was traversed at a speed of $10 \mathrm{~mm} / \mathrm{min}$. Loads corresponding to the onset of surface cracking $\left(L_{C 1}\right)$ and the first instance of substrate exposure $\left(L_{C 2}\right)$ were determined using optical microscopy and their values based on the observation of damage events - as described in BS EN 1071-3:2005 [13].

\subsection{Impact wear testing}

Ball-on-plate repetitive impact testing was used to evaluate the resistance of coatings to dynamic loading and also to assess the effect of triode-plasma diffusion pretreatments on coating adhesion and substrate load-support. The impact tester used in this work is essentially that described in [14], although in this work the piezoelectric force transducer, which outputs the resultant impact force, was relocated to below the sample holder. The impact head assembly holds a WC-Co ball of $6 \mathrm{~mm}$ diameter in a threaded collet and this assembly is rapidly moved upwards and downwards by alternating pneumatic actuation, such that an impact frequency of $8 \mathrm{~Hz}$ is obtained. Each sample was subjected to a range of loading cycles from 1000 impacts up to a maximum of $250 \mathrm{k}$ impacts, at a normal load of $400 \mathrm{~N}$. Selected samples were also tested at a higher impact load of $500 \mathrm{~N}$ for $100 \mathrm{k}$ cycles.

Following impact testing the craters were measured using surface profilometry. A hemi spherical cap geometry was assumed for the wear scars, such that the crater diameter and depth was sufficient to calculate the crater volume. For selected samples volume measurements were also obtained using high-definition 3D maps generated using a Veeco Dektak 150 stylus profilometer, having a traversing

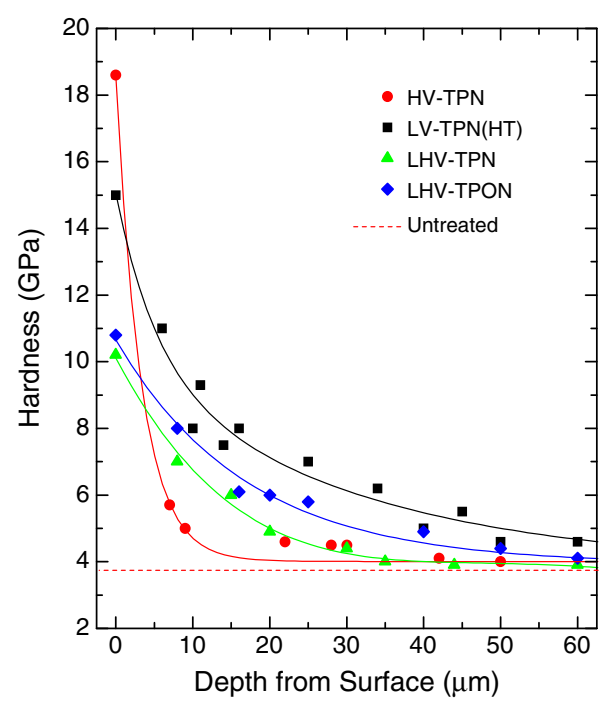

Fig. 1. Hardness-depth profiles of Ti-6Al-4V samples diffusion treated for a total duration of $4 \mathrm{~h}$. 
resolution better than $0.05 \mu \mathrm{m}$ and a vertical resolution less than $0.01 \mu \mathrm{m}$. These showed that the error involved in assuming the above mentioned wear scar geometry was less than $\pm 6 \%$. Thus, this assumption permitted relatively simple yet sufficiently accurate volume measurements - and could therefore be used to provide quantitative estimations of the impact resistance of the tested samples. Finally, impact scars were imaged using optical microscopy and SEM, while energy-dispersive X-ray (EDX) spectroscopy was used to identify any material transfer from the ball and to reveal smaller regions of exposed substrate material.

\section{Results and discussion}

\subsection{Triode plasma diffusion-treated samples}

The hardness-depth profiles of Ti-6Al-4V subjected to four different triode plasma diffusion treatments are shown in Fig. 1. All treatments resulted in an increase in the surface hardness of the titanium alloy; however, substantial differences in treatment effectiveness can be observed. The nitrogen diffusion-strengthened zone in the HT sample is significantly larger than those of the other samples. The increased solute diffusion rate and interstitial solubility at $800^{\circ} \mathrm{C}$, compared to that of the remaining treatments performed at $700{ }^{\circ} \mathrm{C}$, leads to a measurable increase in hardness down to a substrate depth of around $60 \mu \mathrm{m}$. However, treatments performed at $700{ }^{\circ} \mathrm{C}$ were also capable of providing a substantial increase in near-surface hardness, particularly with the combined use of oxygen and nitrogen. The rate of oxygen diffusion in $\alpha$-Ti is known to be much higher than that of nitrogen at a given temperature $[15,16]$ and, more importantly, it is not hindered by the generation of an oxide compound layer at the surface during the oxidation process. In fact, the diffusion coefficient for oxygen in rutile $\mathrm{TiO}_{2}$ is - unlike nitrogen in $\mathrm{TiN} / \mathrm{Ti}_{2} \mathrm{~N}$ - about 50 times higher than in the parent Ti-metal alloy at the same temperature [16]. Conversely, the samples nitrided for $4 \mathrm{~h}$ at a higher substrate negative bias of $1000 \mathrm{~V}$, showed a very high surface hardness, but also a much shallower diffusion-hardened case. A relatively thick $(1.45 \pm 0.1 \mu \mathrm{m})$ nitride compound layer, composed of a mixture of tetragonal $\mathrm{Ti}_{2} \mathrm{~N}$ and face-centred cubic TiN was found to inhibit further nitrogen diffusion into the bulk. In fact, the coefficient of diffusion of nitrogen through $\alpha$-Ti is at least two orders of magnitude higher than for $\delta$-TiN [15] across the entire temperature regime used in this work. Nevertheless, this effect was beneficially harnessed to further improve the surface hardness of (and PVD coating adhesion to) low voltage (LV) diffusion treatments. The reduced formation of surface nitrides during LV nitriding allows a much deeper hardened case to develop (at the same treatment temperature/time); however, it was found through systematic experimentation that this effect could be further enhanced in combination with a single hour of oxidation at the

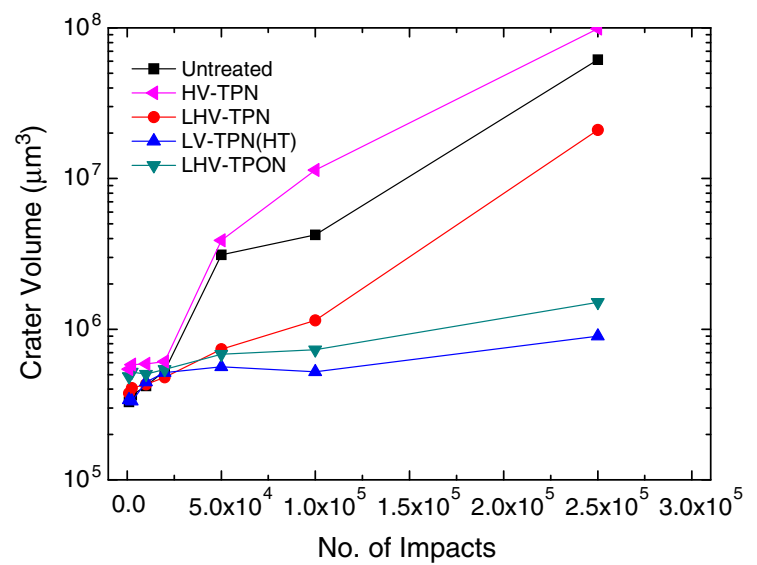

Fig. 2. Indentation volumes obtained in impact tests of untreated and diffusion-treated Ti-6Al-4V at $400 \mathrm{~N}$ load. beginning of the process (to maximise case depth) and a final hour of nitriding at an increased substrate negative bias of $1000 \mathrm{~V}$ (to maximise surface hardness). The benefit of such an improved LHV-TPON three-stage treatment process can clearly be seen in Fig. 1.

Fig. 2 shows the impact wear volumes of untreated and selected triode plasma diffusion-treated samples as a function of the number of impacts at a $400 \mathrm{~N}$ load. Generally, for all samples, both crater diameter and depth increased with increasing number of impacts, resulting in a larger indentation volume. Initially all craters, independent of the specific sample, reached a volume of around 350 to $450 \times 10^{3} \mu \mathrm{m}^{3}$ very rapidly. This is equivalent to a (maximum) crater depth of approximately $4.5 \mu \mathrm{m}$. Indeed, very short experiments (of as little as one impact cycle) on different samples have shown that an indentation of 2.2 to $2.6 \mu \mathrm{m}$ in depth forms immediately. However, a very clear distinction can be made between different samples after around 20k impact cycles. The samples which exhibit a noticeable increase in wear volume include the untreated Ti-6Al-4V alloy, the samples treated continuously at a high negative substrate bias i.e. HV-TPN and (to a lesser degree) the samples which included $1 \mathrm{~h}$ (out of 4 ) at an increased substrate negative bias of $1000 \mathrm{~V}$ i.e. LHV-TPN. From these results some important deductions can be made, as outlined in the following section.

Initially, the untreated material exhibits considerable permanent deformation; however, the rate of growth of the crater volume slows down rapidly. This can be attributed to two main factors. The first is related to a process known as 'shakedown, caused by the repetitive loading applied $[17,18]$. The maximum (initial) Hertzian contact stress for a $6 \mathrm{~mm}$ diameter WC-Co ball impacting at a normal load of $400 \mathrm{~N}$ against a polished Ti-6Al-4V surface (in the untreated condition) was calculated to be $\sim 4.7 \mathrm{GPa}$. Thus, the elastic limit of the substrate material is immediately exceeded upon the first impact, and therefore deformation hardening can occur. Also, a system of residual stresses is likely to be retained in the near-surface material which has been subjected to the indenter stress field; these (compressive) stresses act to hinder yielding during subsequent impacts. Both this stress field and the degree of work hardening below the impact region accumulate with each subsequent impact cycle, increasing the portion of deformation which remains elastic. The loading can then be accommodated in purely elastic deformation (until the elastic shakedown limit is reached). In the case of diffusion-treated samples this effect is enhanced by the presence of residual compressive direct stresses generated by supersaturation of oxygen and nitrogen. X-ray stress analysis data, presented in [19], shows that diffusion-treated samples such as those discussed here tend to exhibit a surface compressive stress ranging between 750 and $900 \mathrm{MPa}$. A second reason for the rapid reduction crater volume growth is that, as the test proceeds, the contact area increases (albeit at a progressively slower rate) and the pressure exerted by the ball falls rapidly (with the rate of increase in indentation volume declining accordingly). Nevertheless, at around 20k impacts the rate of crater volume growth starts to increase again, reaching a depth of around $80 \mu \mathrm{m}$ by $250 \mathrm{k}$ impact cycles. The behaviour of the untreated material can be explained by the embrittlement of the surface under the indenter due to excessive work hardening generated by the compacting force, with resultant fragmentation and exfoliation of the near-surface regions due to sub-surface fatigue crack initiation and growth.

Similar arguments can be made regarding the HV-TPN sample, which remains notionally untreated beyond $\sim 5 \mu \mathrm{m}$ below the surface. This particular sample suffered significantly worse damage - even after short tests of less than $10 \mathrm{k}$ impact cycles. This can be related to characteristics imparted by the thermochemical treatment. Firstly, HV-TPN samples exhibit substantial surface roughening generated by high-energy ionised gas species bombardment. Following a $4 \mathrm{~h} \mathrm{ni-}$ triding treatment at a substrate negative bias of $1000 \mathrm{~V}$, the treated surface experiences a large increase in roughness $\left(R_{a} \sim 0.12 \mu \mathrm{m}\right)-$ due to the growth of faceted nodular nitride protuberances. In turn, these asperities can be easily broken off by the impacting WC-Co ball. Such roughening effects have been proven to lead to high local 
stress concentrations, potentially exceeding the values predicted by Hertz [20,21]. Indeed, even small roughness values (within the scale of significance of this work) can substantially alter the stress field distribution, creating local peaks under asperity tips in loaded contact. Secondly, the thin, hard (and relatively unsupported) nitride compound layer formed in the HV-TPN treatment can substantially be easily fractured and delaminated under dynamic loading. The latter factor could be potentially more significant - since early failure of this hard compound layer leads to the introduction of loose particles to the contact surfaces, which could lead to three-body abrasive wear as these particles are forced into (and across) the impact wear crater. In comparison, the lower surface roughness of a sample subjected to LHV-TPN $\left(R_{a} \sim 0.07 \mu \mathrm{m}\right)$ treatment is reflected in smaller craters developed following short tests, while the deeper hardened case and the absence of a thick nitride compound layer leads to a much slower wear progression - and overall smaller crater development.

Fig. 2 also includes two more samples which show negligible increase in impact wear (up to the limiting number of test cycles applied in this work). Both LV-TPN(HT) and LHV-TPON have already been proven to create a deeper diffusion zone. In the former, the increased resistance to impact is attributed to the higher diffusion coefficient of nitrogen at $800{ }^{\circ} \mathrm{C}$ compared to the other diffusion treatments

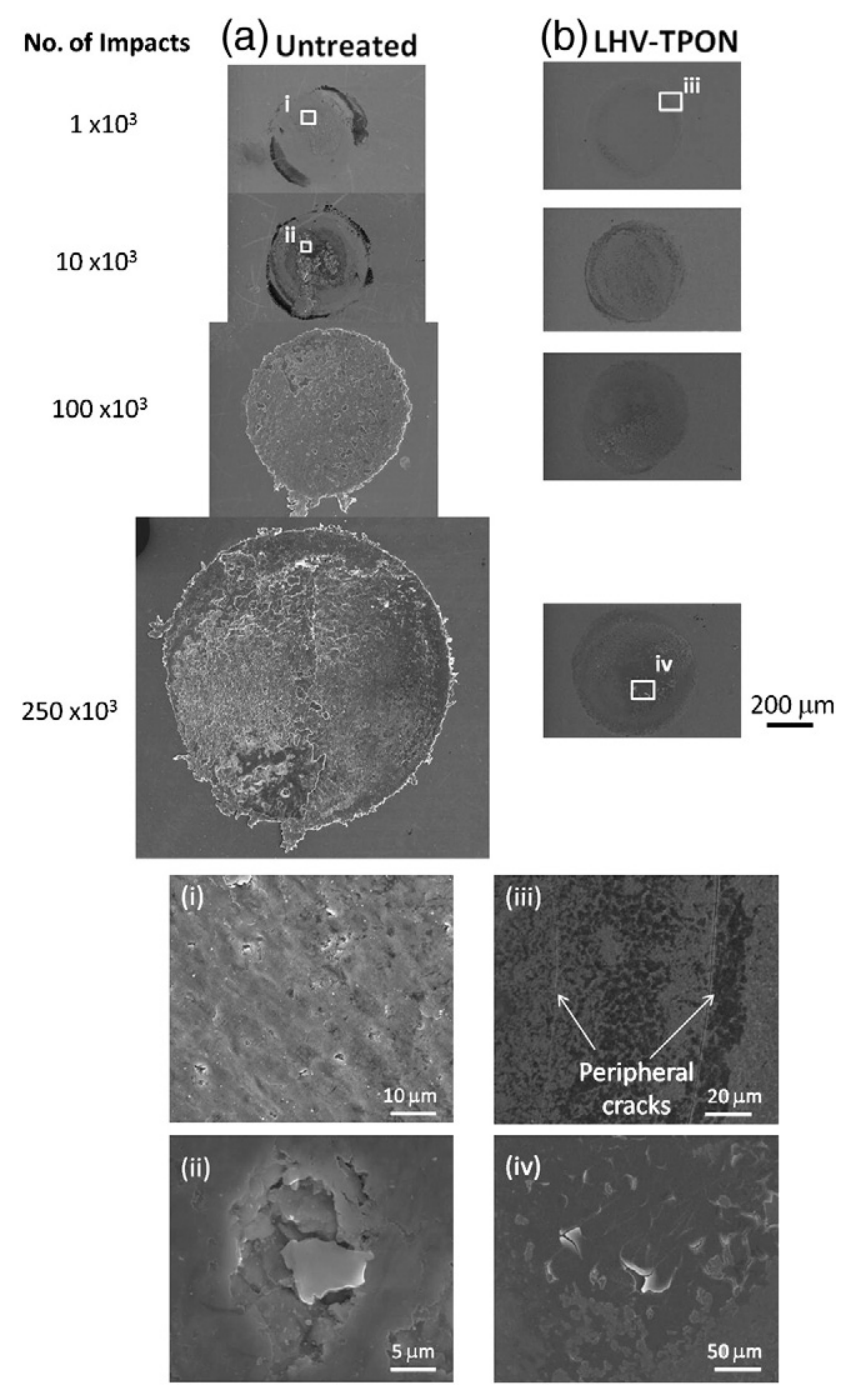

Fig. 3. SEM micrographs of several impact craters of (a) untreated and (b) LHVTPON-treated Ti-6Al-4V when tested at $400 \mathrm{~N}$ load for $1 \mathrm{k}$ to $250 \mathrm{k}$ impact cycles. Images (i) to (iv) show higher magnification micrographs of damaged regions in the untreated samples and in samples which have been oxidised and subsequently nitrided including material deformation, cracking, surface chipping and material transfer from the counterface ball. performed at $700{ }^{\circ} \mathrm{C}$; in the latter, the use of oxygen diffusion is clearly very beneficial and allows similar results to LV-TPN $(\mathrm{HT})$ to be achieved at the lower temperature, by taking advantage of the significantly higher diffusion rate of oxygen through the titanium lattice. SEM inspection of a number of craters (Fig. 3) reveals how triode plasma diffusion processes not only affect the size of the indentation formed, particularly following a large number of impacts, but also the morphology of the wear crater surface. The surface of the impact cavity of the untreated material immediately shows signs of considerable plastic deformation and as the material flows under the spherical indenter, Ti grains are fractured and pulled out, as can be seen in Fig. 3a. When the surface has experienced a sufficient degree of cold work, large areas start to exfoliate, creating numerous micro-cavities and third body particles (Fig. 3b), thereby accelerating the wear rate. These detached particles rapidly oxidise in air - as shown by the EDX spot analysis of material adhered to the ball surface (Fig. 4a, Spectrum 1). In comparison, the LHV-TPON-treated alloy shows no signs of cohesive failure within the central region of the scar. Peripheral circular cracks form almost immediately around the crater (Fig. 3c); however, these do not seem to adversely affect the wear resistance of the treated surface - such cracks appear practically unchanged after $250 \mathrm{k}$ cycles. According to Hertzian contact theory [22,23], the border region where these cracks form is the zone experiencing the highest tensile stresses. These cracks serve to partially dissipate the impact energy by brittle fracture rather than by plastic yielding - due to the higher hardness (and consequently lower ductility) of the treated surface. More recently, Bouzakis and Siganos [21] have shown that the maximum superficial stress in a coated system subjected to impact tests does not exactly coincide with the maximum impact force. While the latter reaches its maximum at the outside contact circle, the former is slightly shifted towards the centre of the contact area. This could explain why the first instance of peripheral cracking was typically observed inside the contact circle, within a few tens of microns of the outside crater diameter.

On the surface of the LHV-TPON-treated sample it is also possible to observe a transfer layer from the WC-Co ball which progressively covers larger portions of the impact crater (Fig. 3d). In fact, the ball was also found to suffer progressive surface degradation, experiencing continuous detachment of particles from its surface. Fig. 4b compares the EDX spectra of the transfer layer and the underlying substrate material. Spectrum 2 shows a significant presence of $\mathrm{W}$ and Co while Ti is still detectable from the material below this layer. Oxygen is also detected due to oxidation of this transfer layer. This is due to the shallow nature of the transfer layer, the thickness of which is less than the penetration depth of the electron beam. Conversely, spectrum 3 shows no presence of elements from the ball material; instead, nitrogen (together with the principal elements of Ti-6Al-4V) was detected. This reflects the fact that, eventually, these platelets of transferred material can peel off - but without inducing severe wear in the treated surface.

\subsection{PVD-coated samples (on untreated substrate)}

Fig. 5 shows the results obtained after impact testing three different coatings on a Ti substrate which had not been pretreated. TiN and WC/C exhibit a significant increase in wear crater size (particularly beyond 10k impact cycles), while CrAlN appears not to suffer extensive wear up to the maximum number of impacts used in this work.

The non-duplex TiN is unable to accommodate the large substrate deformations under impact loading. After only 1000 impacts, the surface of the crater becomes distorted and, as the test duration increases, surface roughening becomes more pronounced until adhesive failure starts to occur between $20 \mathrm{k}$ and $50 \mathrm{k}$ impact cycles.

The onset of circular macro-cracking in TiN at 10k cycles is clearly noticeable, Fig. 6a. During the early stages of impact testing, the lowyield strength of the substrate under the coating allows gross plastic deformation to occur, creating an indentation cavity where the coating is being stretched. The repetitive (elastic) tensile stretching that occurs inside the cavity as the test progresses to higher numbers of cycles results 

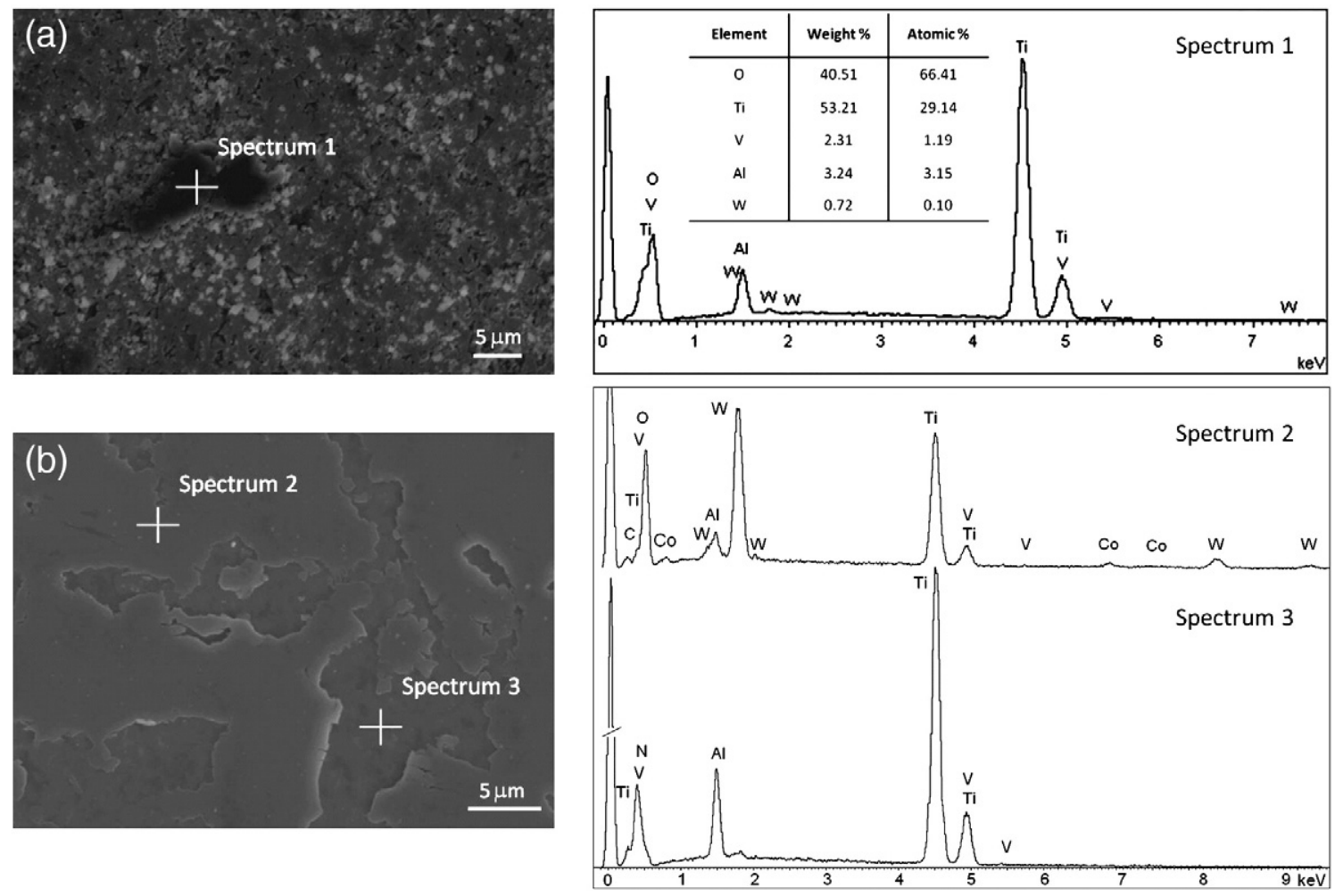

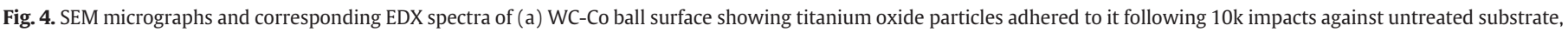
and (b) central portion of crater of a LHV-TPON-treated sample following $50 \times 10^{3}$ impacts.

in fatigue stressing of the PVD coating, which in turn has to be relieved in the form of surface energy in newly generated cracks. In the case of TiN, the circumferential cracks (initially present only around the crater edge) multiply towards the imprint centre and, between $10 \mathrm{k}$ and $20 \mathrm{k}$ impacts, these cracks interconnect radially to form an extensive network covering the entire crater surface, Fig. 6b. This image also shows patches of transferred material from the ball; again, the shallow nature of this transfer layer is evidenced by the formation of interference fringes, visible under the optical microscope. Finally, the coating fractures in very small segments of around $1 \mu \mathrm{m}$ in length and then separates from the underlying material, Fig. 6c. Thus, it can be concluded that nonduplex TiN fails due to rapid adhesive and cohesive failure, coupled with the transfer of material from the ball to the sample and vice-versa.

In comparison, while the volume of the scar (and therefore the degree of plastic strain of the substrate) for $\mathrm{WC} / \mathrm{C}$ and TiN-coated Ti-6Al$4 \mathrm{~V}$ at $50 \mathrm{k}$ impacts is practically identical (Fig. 5), WC/C shows no sign

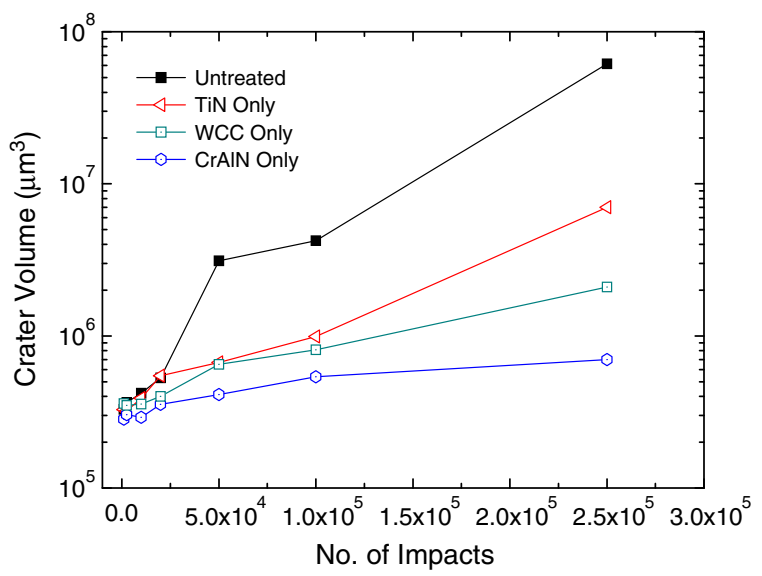

Fig. 5. Indentation volumes obtained in impact testing of untreated and PVD-coated Ti-6Al-4V at $400 \mathrm{~N}$ load. of delamination. Although some cohesive failure occurs (Fig. 6d), substrate exposure cannot be observed; consequently, surface damage is more contained and no catastrophic failure is triggered. Another important difference between the two is that practically no adhesive wear products can be observed on the surface of the WC/C-coated substrate. The absence of a transferred layer in this case lowers the chemical compatibility of the mating surfaces, thereby reducing the likelihood of adhesive failure. Also, the lower surface friction between the impacting ball and the carbonatious layer (compared to the PVD nitride coating) decreases further the probability of adhesive failure. The only material visible around the crater (as indicated by EDX analysis) is oxidised debris from the WC-Co ball. In comparison, CrAlN-coated surfaces reveal moderate amounts of material transfer from the ball counterface. This is mostly found piled up at the crater edges in the form of oxidised wear products (Fig. 6e). Also, no microcracks were observed under optical microscopy investigation when single-layered CrAlN samples were tested at $400 \mathrm{~N}$ normal load up to $250 \mathrm{k}$ impact cycles.

Clearly, the mechanical characteristics of the coatings play an important role - particularly the hardness, $H$ and the elastic modulus, $E$. Tsui et al. [24] showed that the Hertzian contact stress equations, together with Tabor's observation that typically the measured hardness of a material is approximately three times its yield strength [25], can be used to demonstrate that relative resistance to plastic deformation for such a contact geometry is described by the parameter $H^{3} / E^{2}$. Assuming a Poisson's ratio of 0.25 for CrAlN [26] and of 0.22 for TiN $[27,28]$ - and using the reduced elastic moduli measured by nanoindentation - the (calculated) elastic moduli for these two coatings are approximately $364 \mathrm{GPa}$ and $466 \mathrm{GPa}$, respectively. The nanoindentation hardness was measured to be $32.1 \mathrm{GPa}$ and $26.2 \mathrm{GPa}$ for $\mathrm{CrAlN}$ and TiN, respectively. The resultant higher ratio of $H^{3}$ to $E^{2}$ for CrAlN (0.28) compared to TiN (0.08) may again be a principal factor in the remarkable performance of the former under dynamic impact wear testing $[25,29]$. Several authors have indeed verified a direct correlation between coating wear performance and this parameter (or, in many cases, the $H / E$ ratio) under a variety of different tribological tests, such as pin-on-disk, reciprocating-sliding, scratch, 


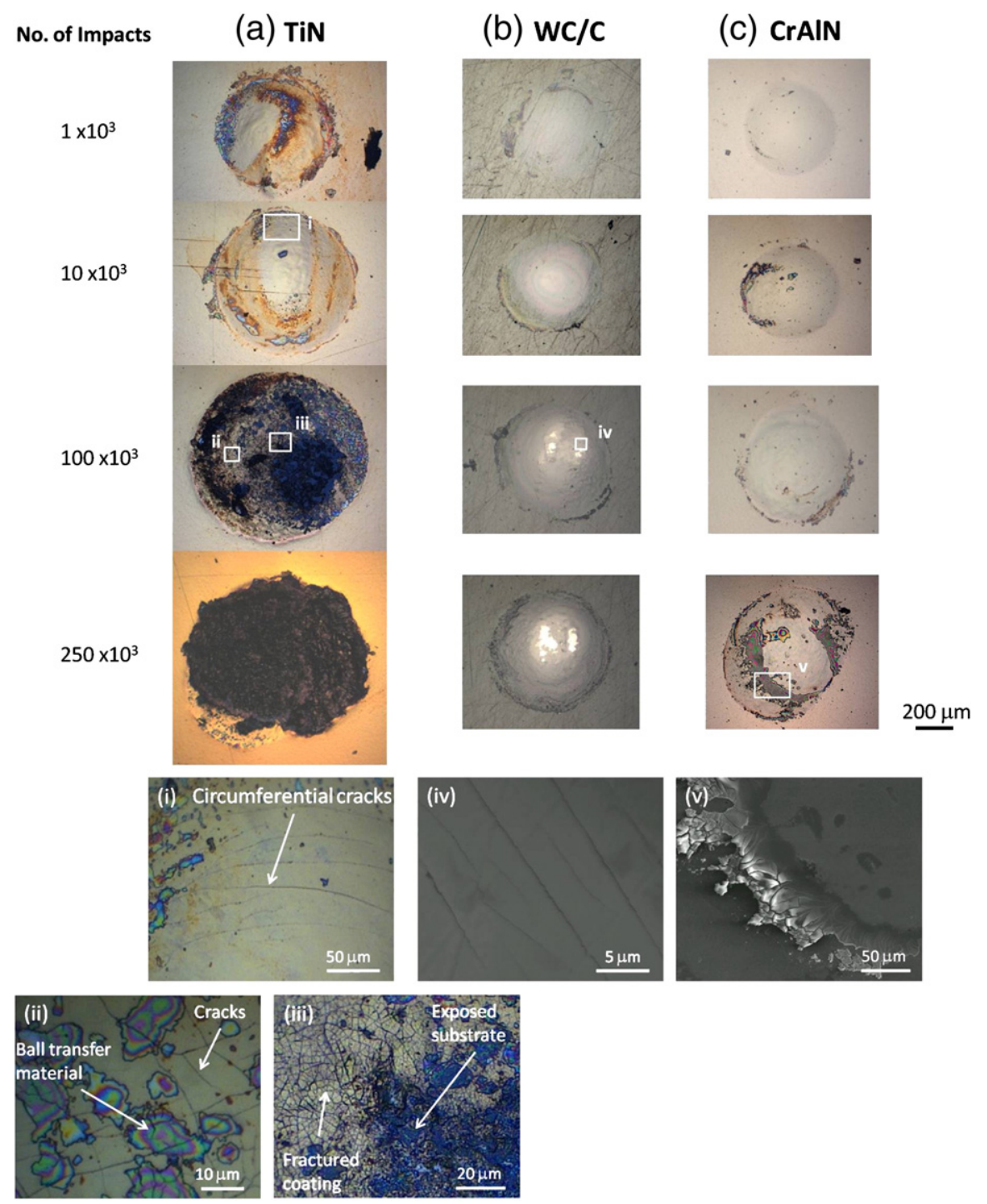

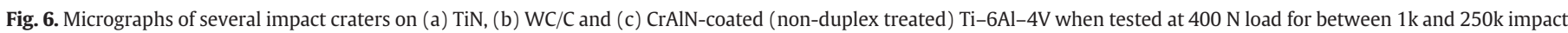
cycles. Magnified images (i) to (v) show typical damaged regions in the coatings, including cracking, delamination and material transfer from the ball counterface.

nanoindentation, and micro-abrasion wear [29-33]. CrAlN is not only more capable of withstanding the cyclic loading exerted by the ball, but also of substantially reducing the overall deformation of the coatingsubstrate system. It should be emphasised that, since the load (rather than the contact pressure) was maintained constant during the test, samples coated with CrAlN can be considered to have endured higher pressures (and stresses) for the majority of the test, as the 'real' contact area remains significantly smaller than for TiN.

The apparent superiority of CrAlN (compared to TiN) on untreated Ti-6Al-4V was explored further, to understand whether this technical advantage would be maintained at higher impact loads. Increasing the impact load from 400 to $500 \mathrm{~N}$ (and measuring crater volumes after $100 \mathrm{k}$ impacts) shows that the difference between the two coatings is reduced to $\sim 20 \%$ (compared to $\sim 56 \%$ at $400 \mathrm{~N}$ ). At this higher impact load CrAlN is incapable of enduring the pressure applied below the indenter ball. Thus, the coating fails catastrophically, showing signs of both adhesive and cohesive failure. The coating was also found to delaminate outside the area of direct contact with the ball. A region extending radially to around $150 \mu \mathrm{m}$ outside the contact diameter had been detached from the substrate. The EDX maps shown in Fig. 7 confirm the regions where the coating has been removed and also reveal the central contact zone, which is rich in $\mathrm{W}$ and $\mathrm{O}$. The presence of these two elements (in smaller quantities) outside the contact crater is due to scattered debris and, in the case of $\mathrm{W}$, this is due to minor contamination during coating deposition by the electron-emitting $\mathrm{W}$ filament used to intensify the plasma. During the treatment process, the $\mathrm{W}$ filament is continuously bombarded by ionised $\mathrm{Ar}$ and $\mathrm{N}$ species and thus some material may either be sputtered onto the substrate being coated or $\mathrm{W}$ may evaporate due to the high electric current passing through it (and consequent heat generation.

Finally, the difference in failure mode of CrAlN compared to TiN can also be correlated to the adhesion strength of the two coatings and particularly to the higher cohesive strength of the former. Scratch adhesion measurements prove that the cohesive (denoted by $L_{C 1}$ ) and adhesive (denoted by $L_{C 2}$ ) strength of CrAlN is superior to that demonstrated by TiN when deposited on an untreated Ti-alloy substrate (Fig. 8). The negligible $L_{C 1}$ value of TiN corresponds to the observed early onset of circumferential cracking during impact tests while, once the load is sufficiently high, delamination from the substrate can also occur.

\subsection{Duplex-treated samples}

Fig. 9 shows the change in crater volume with increasing number of impact cycles for duplex diffusion-treated/PVD-coated samples. The most marked difference that is noticeable when comparing the 

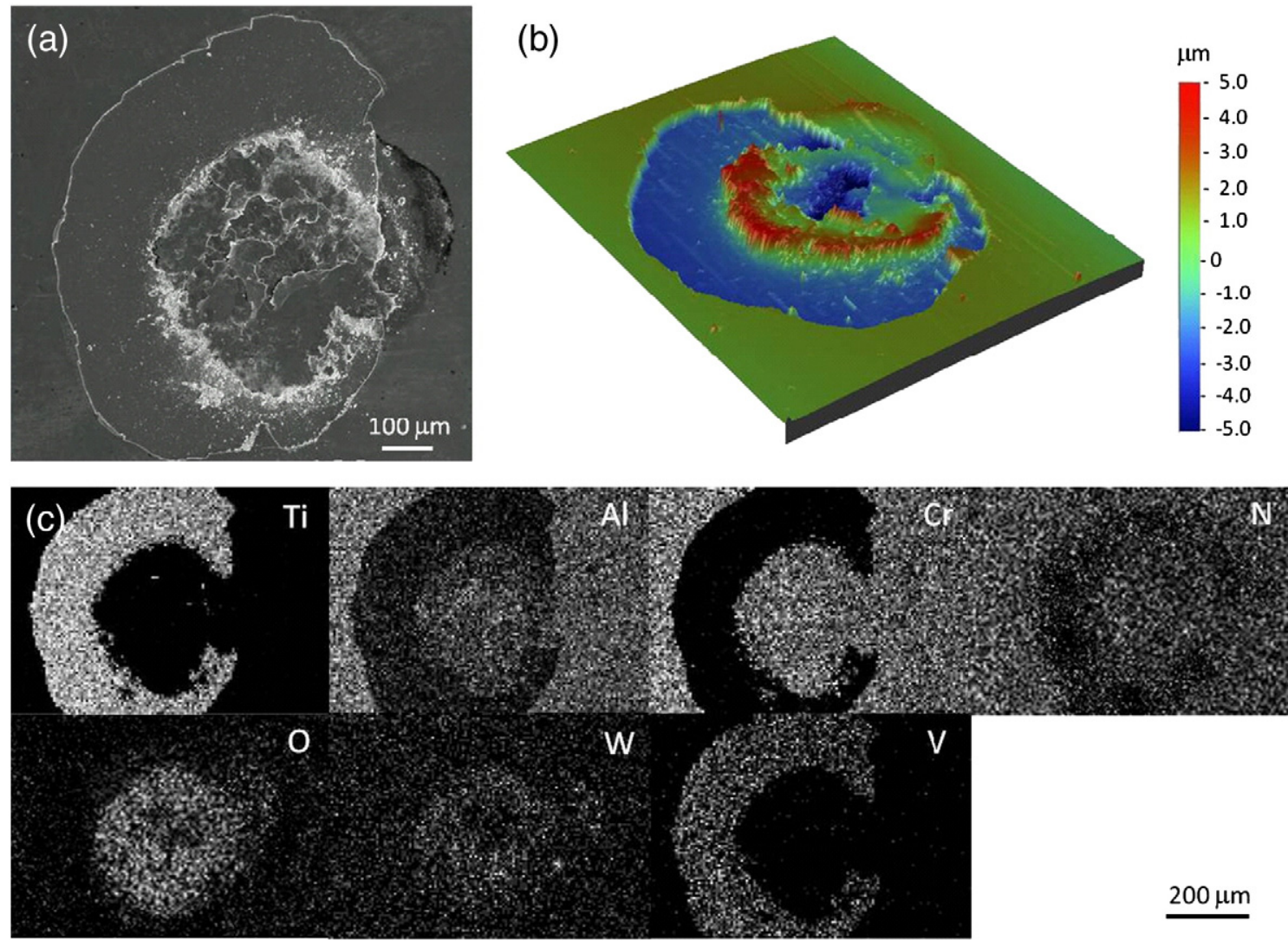

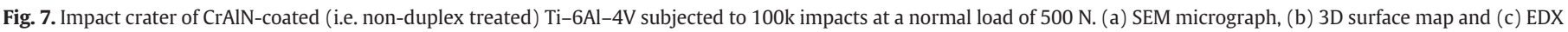
elemental maps.

plots with those presented in Fig. 5 is the absence of a rapid increase in wear for the duplex TiN-coated sample above 100k impacts; in particular, the impact crater volume hardly changes up to $250 \mathrm{k}$ impacts. In fact, the wear volume is barely $20 \%$ of that seen for the single-layer TiNcoated alloy at this point. Based on similar results already reported for duplex plasma diffusion-treated/PVD-coated metal substrates [3], this may initially be attributed to increased load-support for the coating, minimising substrate deformation and thereby reducing the bending and stretching which needs to be accommodated by the (less compliant) coating. However, a closer observation of the remaining data points

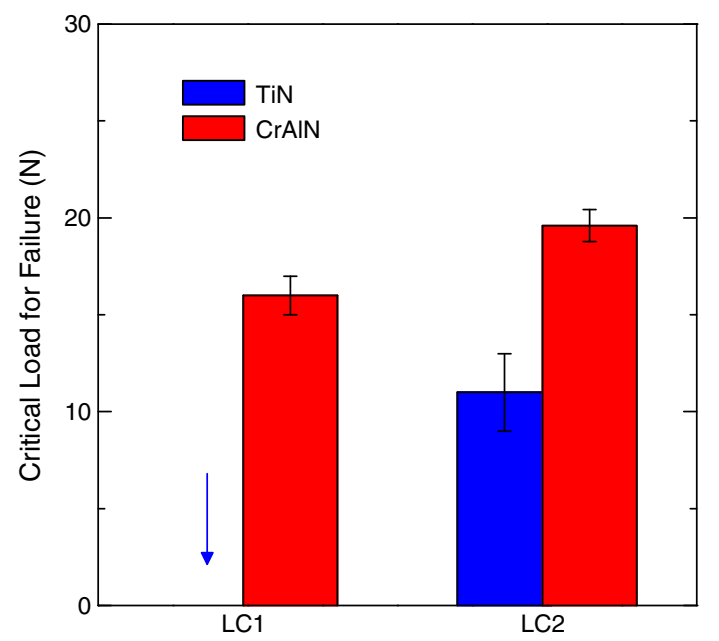

Fig. 8. Critical scratch loads for failure of $2.8 \mu \mathrm{m}$ TiN and $2 \mu \mathrm{m}$ CrAlN coatings deposited on untreated Ti-6Al-4V samples. (i.e. $<100 \mathrm{k}$ impacts) for both TiN and CrAlN suggests otherwise. By comparing impact wear data for CrAlN-coated samples shown in Figs. 5 and 9, it can be seen that the measured wear craters for these samples are larger in the case of the duplex-treated/coated (rather than non-duplex coated) samples. Similarly, this is the case for TiNcoated specimens. These observations were made for a variety of duplex diffusion-treated/PVD-coated Ti-alloy samples subjected to dynamic impact testing and were practically independent of whichever triodeplasma diffusion treatment was performed before depositing either TiN or CrAlN.

At very low number of impact cycles (ie. $\leq 10 \mathrm{k}$ impacts), the increased surface roughness of the duplex samples is also likely to be a contributory factor in their resultant larger wear craters. However, for longer

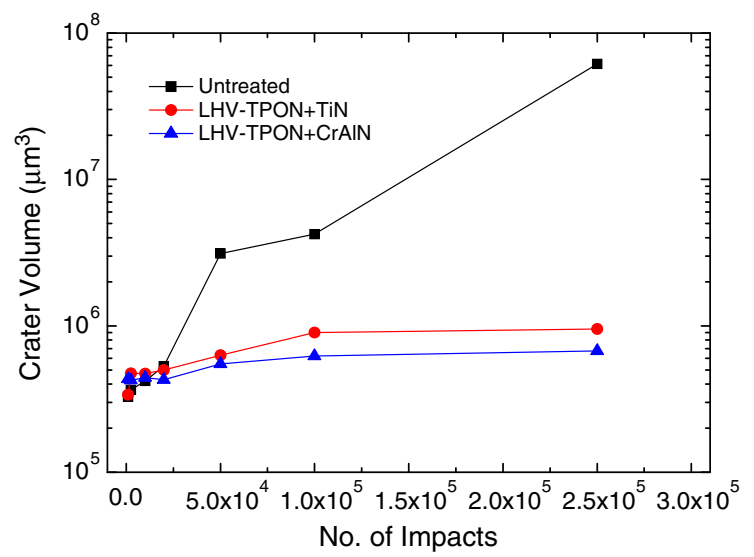

Fig. 9. Indentation volumes obtained in impact testing of untreated and duplex diffusion-treated/PVD-coated Ti-6Al-4V at $400 \mathrm{~N}$ load. 
tests (producing larger scars), the effect of the initial surface condition of the sample becomes progressively less important. It is believed that changes in the bulk mechanical properties of the substrate material (resulting from the diffusion pre-treatment) may be responsible for the observed increase in crater volume. Uniaxial tensile testing of untreated Ti-6Al-4V [34] revealed that the ultimate tensile strength (UTS) was around $1065 \mathrm{MPa}$; i.e. within the typical range for this alloy [35,36]. However, following diffusion treatments held at $700{ }^{\circ} \mathrm{C}$ the measured UTS dropped by around 7\%. This could be attributed to several microstructural aspects discussed in [19]; including changes in the $\beta$-phase content, increase in the $\alpha$-phase mean grain size and a reduced anisotropy of the mechanical properties (due to a more equiaxed microstructure) following the treatment. Typically, for impact tests lasting between 1000 and 50k impacts the increase in crater volume for duplex-treated samples was around 5 to $12 \%$ larger than craters measured on PVD-coated samples which had not been previously plasma diffusion treated.

Having established earlier that strengthening of the substrate near-surface occurs with the interstitial diffusion of solute elements, it is important to compare the effective depth of the strengthened zone with the range of the applied stress field. Calculations based on Hertzian contact theory [22] for the first impact - on a smooth, untreated Ti-6Al-4V surface - suggest that an impact load of $400 \mathrm{~N}$ generates a contact radius of approximately $200 \mu \mathrm{m}$. This estimation seems to be sufficiently accurate, since direct imprint measurements taken following tests of 10 impact cycles or less showed impact crater radii of $213 \pm 12 \mu \mathrm{m}$. According to the stress distribution described by Hertz, for a $6 \mathrm{~mm}$ diameter perfectly-elastic hard sphere loaded against a flat plate, the maximum shear stress occurs at a depth equal to half the contact radius, while its magnitude is approximately equal to half the mean pressure of the spherical contact. Thus, the highest substrate shear stress occurs at $\sim 110 \mu \mathrm{m}$ depth and has a calculated magnitude of $1.42 \mathrm{GPa}$; plastic flow occurs when the shear stress in the material reaches a critical value equal to half the yield strength in uniaxial tension [37]. Clearly in this case, plastic flow occurs, since the maximum shear stress is much higher than $415 \mathrm{MPa}$ (which is $0.5 \sigma_{y}$ for Ti-6Al-4V); more importantly, this value is reached well below the measurable case depth in LHV-TPON samples. Thus small changes in bulk material properties are very likely to affect significantly the deformation resistance of the material supporting the entire diffusion-treated case. The effect generated by the associated thermal cycle on the mechanical properties of the alloy has already been discussed above and in [19], while also correlating the observed differences with the changes in the material microstructure.

In order to differentiate between the effect of changes in bulk microstructure of the Ti alloy and of surface hardening achieved (following diffusion treatment) another experiment was designed. An impact coupon sample was shielded (in stainless steel foil) and treated together with a triode-plasma diffusion process, such that it was exposed to the same thermal cycle experienced by a plasma diffusiontreated sample, whilst at the same time retaining the surface condition (chemistry and topography) of the untreated alloy material. This 'plasma annealed' sample was then coated with TiN and impact tested. The results showed that the impact craters were larger than for single-layer (non-duplex) TiN-coated samples - i.e. when compared to coated samples not exposed to the higher (diffusion) process treatment temperature $\left(700{ }^{\circ} \mathrm{C}\right.$ vs. $\left.400-450{ }^{\circ} \mathrm{C}\right)$. Duplex treated/coated samples however exhibited significantly smaller crater volumes than either of the above, indicating that the strengthened surface layer contributed - albeit to a limited extent - to a reduction in the plastic deformation of the material under dynamic impact wear.

As already highlighted above, once the number of impacts increases above $100 \mathrm{k}$, the volume of the craters formed in duplex-treated samples becomes less than that of single-layered counterparts. This is however due primarily to the enhanced durability of the PVD coating when deposited on a diffusion pretreated surface - and not because of an overall reduction in plastic flow. While the TiN coating on a non- duplex treated sample quickly starts to crack (and eventually debonds from the untreated substrate), the cracking observed on the duplex sample is much less severe and no large-area adhesive failure is seen, Fig. 10. In turn, the effectiveness of the coating in offering resistance to failure is extended to a much larger number of impact cycles. In the case of CrAlN-coated samples, the same comparison cannot be made at a testing load of $400 \mathrm{~N}$, but impact craters generated when the impact load is increased to $500 \mathrm{~N}$ show drastic differences in coating performance. Fig. 10 shows a duplex diffusion-treated and CrAlN-coated sample tested at $500 \mathrm{~N}$ for $100 \mathrm{k}$ impacts. The crater shown can be contrasted with that presented in Fig. 7 for single-layer (non-duplex treated) CrAlN. The damage in the duplex-treated sample is minimal compared with non-duplex CrAlN tested under identical conditions. Contrary to the images shown for CrAlN alone, the EDX spectra presented in Fig. 10 show practically no difference between the material present inside and outside the crater area (spectrum 1 vs. 3 ) for the duplex-treated sample - demonstrating that the coating was virtually intact after testing. The only trait observable in the wear scar of the duplex diffusion-treated/CrAlN-coated sample is small quantities of oxidised debris (originating mainly from the WC-Co ball), which accumulated at the edge of the contact patch. In fact, EDX spectrum 2 shows peaks corresponding to $\mathrm{W}$, Co and $\mathrm{O}$ superimposed on the peaks associated with the CrAlN coating. These results highlight the fact that improved coating adhesion $[10,38]$ provided by the plasma diffusion treatment is likely to be the main contributor to the overall improved response of duplex-treated samples under dynamic, repetitive impact wear testing.

\section{Conclusions}

Triode-plasma diffusion treatments and PVD ceramic coatings were evaluated separately, and in duplex combinations, under dynamic ball-on-plate impact testing. Observations made were based on the volume of the wear scar produced (as a measure of the deformation sustained by the near-surface material), and qualitative inspection of the impact crater surface morphology.

As expected, untreated Ti-6Al-4V is shown to be extremely vulnerable to such impact wear conditions; nevertheless, the results presented here show that triode-plasma diffusion treatments (even without a subsequently deposited PVD hard coating) can provide outstanding improvements in impact fatigue resistance. This is proven by the reduced crater volumes for all numbers of impacts applied - and by the large reduction in surface damage. Diffusion-treated samples exhibit signs of cohesive failure, some peripheral circular cracks and (oxidised) material adhesive transfer from the impinging WC-Co ball; however, this damage tends not to adversely affect the (substantially improved) durability of the surface.

PVD coatings can also impart good protection against dynamic impact wear. In particular, WC/C and CrAlN exhibit excellent adhesive and fatigue strength - the combination of a lower coefficient of friction and higher deformability and/or compliance (compared to TiN) contributes to the better impact-fatigue resistance of these coatings. In the case of CrAlN, its combination of high hardness and relatively low elastic modulus (i.e. a high $\mathrm{H} / \mathrm{E}$ ratio, with coating elastic modulus closer to that of the underlying substrate) leads to practically no increase in wear volume under the testing conditions used in this work.

For samples which had been diffusion treated prior to coating, the 'steady-state' region of no discernable wear scar growth (with increasing number of impact cycles) was extended when compared to samples which were only PVD coated. Interestingly, the deformation volume measured for duplex-treated samples was found in some cases to be slightly higher than for non-duplex samples, particularly in relatively short impact tests. This was attributed to some degree of softening in the substrate alloy during the diffusion pretreatment. The otherwise reduced crater size in duplex samples appears to 


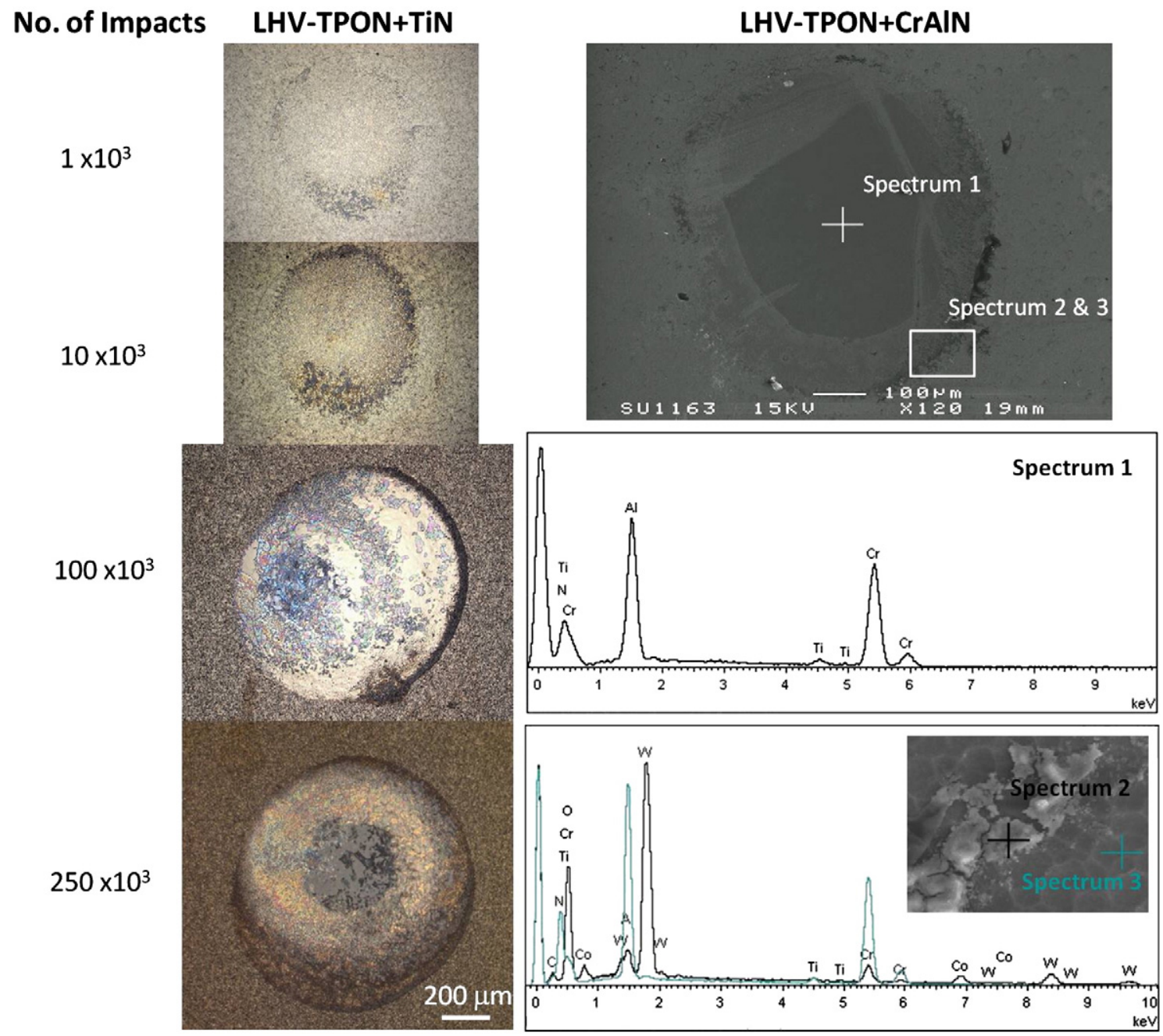

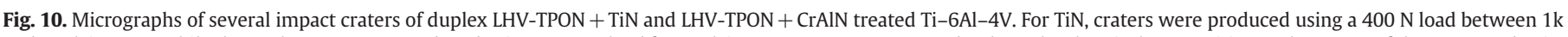

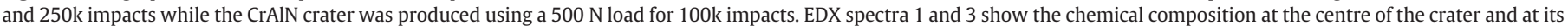
periphery, respectively; while spectrum 2 was taken from accumulated debris around the crater periphery.

occur mainly as a consequence of the improved adhesion and higher resistance to fatigue crack growth of coatings deposited on a pretreated surface - rather than due to any reduction in deformability of the surface. In order to reduce this effect, the diffusion treatment time should be extended such that the region of maximum shear strain below the surface is confined within a deeper (i.e. several hundred microns thick) diffusion zone. Nevertheless, the performance of duplex-treated samples with shallow diffusion cases (typically in the range of 25-50 $\mu \mathrm{m}$ deep) is markedly superior and, particularly for the LHV-TPON + CrAlN sample, the surface remained virtually intact even when tested for $250 \mathrm{k}$ cycles at an impact load of $500 \mathrm{~N}$.

\section{Acknowledgements}

The authors gratefully acknowledge financial support from the UK Technology Strategy Board under Technology Programme project TP/ 22076, for underpinning research carried out at Sheffield University on which the work presented in this paper was partially based.

\section{References}

[1] O. Knotek, B. Bosserhoff, A. Schrey, T. Leyendecker, O. Lemmer, S. Esser, Surf. Coat. Technol. 54/55 (1992) 102

[2] X. Li, P. Wu, B. Tang, J.-P. Celis, Vacuum 79 (2005) 52.

[3] J.C.A. Batista, C. Godoy, A. Matthews, Surf. Coat. Technol. 163-164 (2003) 353

[4] K.-D. Bouzakis, A. Asimakopoulos, M. Batsiolas, Surf. Coat. Technol. 202 (2008) 5929.
[5] K.-D. Bouzakis, N. Michailidis, S. Gerardis, G. Katirtzoglou, E. Lili, M. Pappa, M. Brizuela, A. Garcia-Luis, R. Cremer, Surf. Coat. Technol. 203 (2008) 781.

[6] A. Wilson, A. Matthews, J. Housden, R. Turner, B. Garside, Surf. Coat. Technol. 62 (1993) 600.

[7] A. Wilson, A. Leyland, A. Matthews, Surf. Coat. Technol. 114 (1999) 70.

[8] G. Cassar, J.C. Avelar-Batista Wilson, S. Banfield, J. Housden, A. Matthews, A. Leyland, Wear 269 (2010) 60

[9] Y. Birol, Trans. Nonferrous Met. Soc. China 20 (9) (2010) 1656.

[10] A. Leyland, K.S. Fancey, A. Matthews, Surf. Eng. 7 (3) (1991) 207

[11] A. Leyland, K.S. Fancey, A.S. James, A. Matthews, Surf. Coat. Technol. 41 (1990) 295.

[12] BS EN ISO 4545-1, Metallic Materials - Knoop Hardness Test - Part 1: Test Method, 2005, p. 1, BSi.

[13] BS EN 1071-3, Advanced Technical Ceramics - Methods of Test for Ceramic Coatings - Part 3, 2005, p. 1, BSi.

[14] R. Bantle, A. Matthews, Surf. Coat. Technol. 74-75 (1995) 857.

[15] F.W. Wood, O.G. Paasche, Thin Solid Films 40 (1977) 131.

[16] J. Unnam, R.N. Shenoy, R.K. Clark, Oxid. Met. 26 (3/4) (1986) 231.

[17] I.N. Dyson, J.A. Williams, A. Kapoor, Proc. Inst. Mech. Eng. Part J 213 (1999) 287.

[18] S.K. Wang, A. Kapoor, J.A. Williams, Wear 203-204 (1997) 162.

[19] G. Cassar, J.C. Avelar-Batista Wilson, S. Banfield, J. Housden, M. Fenech, A. Matthews, A. Leyland, Int. J. Fatigue 33 (2011) 1313.

[20] A. Mihailidis, V. Bakolas, N. Drivakos, Wear 249 (2001) 546.

[21] K.-D. Bouzakis, A. Siganos, Surf. Coat. Technol. 185 (2004) 150.

[22] H. Hertz, , Chp. 5, Math., 1881, Translated, On the Contact of Elastic Solids; Translated and Reprinted in English in Hertz's Miscellaneous Papers, Macmillan \& Co, London, 1896, p. 92, 146-162.

[23] K.L. Johnson, Contact Mechanics, Cambridge University Press, Cambridge, 1985, p. 92, 155.

[24] T.Y. Tsui, G.M. Pharr, W.C. Oliver, C.S. Bhatia, R.L. White, S. Anders, A. Anders, I.G. Brown, Mater. Res. Soc. Symp. Proc. 383 (1995) 447.

[25] D. Tabor, The Hardness of Metals, Oxford University Press, London, 1951, p. 105.

[26] J. Lin, B. Mishra, J.J. Moore, W.D. Sproul, Surf. Coat. Technol. 202 (2008) 322. 
[27] J. Valli, U. Mäkelä, A. Matthews, Surf. Eng. 2 (1) (1986) 49.

[28] M.T. Laugier, J. Mater. Sci. Lett. 2 (1983) 419.

[29] J. Musil, Surf. Coat. Technol. 125 (2000) 322.

[30] M. Woydt, A. Skopp, I. Dorfel, K. Witke, Wear 218 (1998) 84.

[31] A. Leyland, A. Matthews, Wear 246 (2000) 1.

[32] T.Y. Tsui, G.M. Pharr, W.C. Oliver, Y.W. Chung, E.C. Cutiongco, C.S. Bhatia, R.L. White, R.L. Rhodes, S.M. Gorbatkin, MRS Nov-Dec 1994 Conference, Boston, 1995, p. 1.

[33] F.W. Zok, A. Miserez, Acta Mater. 55 (2007) 6365.

[34] G. Cassar, Ph.D. thesis: The University of Sheffield, UK, 2011.
[35] C. Leyens, M. Peters, Titanium and Titanium Alloys: Fundamentals and Applications, Wiley-VCH, 2005, p. 20.

[36] D.H. Kohn, P. Ducheyne, J. Mater. Sci. 26 (1991) 328.

[37] K.C. Ludema, Friction, Wear, Lubrication: A Textbook in Tribology, CRC Press, Boca Raton, 1996, p. 55.

[38] G. Cassar, S. Banfield, J.C. Avelar-Batista Wilson, J. Housden, A. Matthews, A. Leyland, Surf. Coat. Technol. 206 (2011) 395. 